\title{
PEMODELAN RETURN HARGA SAHAM MENGGUNAKAN MODEL INTERVENSI-ARCH/GARCH (Studi Kasus : Return Harga Saham PT Bayan Resources Tbk)
}

\author{
Dea Manuella Widodo ${ }^{1}$, Sudarno ${ }^{2}$, Abdul Hoyyi ${ }^{3}$ \\ 1,2,3 Departemen Statistika, Fakultas Sains dan Matematika, Universitas Diponegoro \\ e-mail :dsghani@gmail.com
}

\begin{abstract}
The intervention method is a time series model which could be used to model data with extreme fluctuation whether up or down. Stock price return tend to have extreme fluctuation which is caused by internal or external factors. There are two kinds of intervention function; a step function and a pulse function. A step function is used for a long-term intervention, while a pulse function is used for a short-term intervention. Modelling a time series data needs to satisfy the homoscedasticity assumptions (variance of residual is homogeneous). In reality, stock price return has a high volatility, in other words it has a non-constant variance of residuals (heteroscedasticity). ARCH (Autoregressive Conditional Heteroscedasticity) or GARCH (Generalized Autoregressive Conditional Heteroscedasticity) can be used to model data with heteroscedasticity. The data used is stock price return from August 2008 until September 2018. From the stock price return data plot is found an extreme fluctuation in September $2017(\mathrm{~T}=110)$ that is suspected as a pulse function. The best model uses the intervention pulse function is ARMA([1,4],0) $(b=0, s=1, r=1)$. The intervention model has a non-constant variance or there is an ARCH effect. The best variance model obtained is $\operatorname{ARMA}([1,4], 0)(b=0, s=1, r=1)-\operatorname{GARCH}(1,1)$ with the AIC value is $-205,75088$.
\end{abstract}

Keywords: Stock Return, Intervention, Heteroscedasticity, ARCH/GARCH

\section{PENDAHULUAN}

Seiring berkembangnya zaman dan kondisi perekonomian Indonesia, orang-orang mulai banyak mencari alternatif investasi untuk masa depan, dalam hal ini pasar modal sangat bermanfaat bagi investor pada umumnya.Salah satu produk investasi di pasar modal yang paling popular adalah saham. Saham didefinisikan sebagai bukti kepemilikan seseorang atau badan atas suatu perseroan (perusahaan) yang merupakan klaim atas penghasilan dan kekayaan perseroan (Bursa Efek Indonesia, 2018).

Salah satu hal yang perlu diperhatikan sebelum membeli saham adalah melihat bagaimana volatilitas saham tersebut sebelumnya. Semakin tinggi volatilitas suatu saham maka semakin tinggi pula risiko saham tersebut.Volatilitas saham yang tinggi ditunjukkan dengan data yang berfluktuasi cepat dari waktu ke waktu.

Seringkali fluktuasi harga saham dipengaruhi oleh kejadian-kejadian khusus. Kejadian khusus ini dapat dikatakan sebagai suatu intervensi baik bersifat eksternal maupun internal yang mempengaruhi pola data (Nuvitasari, 2009). Analisis intervensi sendiri dapat dibagi menjadi 2, yaitu analisis intervesi fungsi step dan fungsi pulse. Analisis intervensi fungsi stepdigunakan untuk intervensi bersifat jangka panjang. Sedangkan analisis intervensi fungsi pulse digunakan untuk intervensi bersifat jangka pendek atau sementara.

Dalam praktiknya, pemodelan runtun waktu pada data ekonomi seringkali memberikan residual dengan varians yang tidak konstan (heterogen). Model runtun waktu yang dapat mengatasi kondisi ini adalah Autoregressive Conditional Heteroskedasticity $(\mathrm{ARCH})$ atau GeneralizedAutoregressive Conditional Heteroskedasticity (GARCH). 


\section{TINJAUANPUSTAKA}

\subsection{Analisis Runtun Waktu}

Runtun waktu adalah sebuah urutan rangkaian observasi yang beruntun. Dasar pemikiran runtun waktu adalah pengamatan pada waktu $t\left(Z_{t}\right)$ bergantung pada satu atau beberapa pengamatan sebelumnya $\left(\mathrm{Z}_{\mathrm{t}-\mathrm{k}}\right)$. Hal mendasar dari analisis runtun waktu adalah korelasi setiap pengamatannya dan pentingnya urutan pengamatan (Wei, 2006). Ada berbagai macam tujuan analisis runtun waktu, termasuk menganalisa pola suatu data berdasarkan deret waktu serta meramalkannya untuk periode waktu ke depan.

\subsubsection{Stasioneritas}

Menurut (Gujarati, 2004) sebuah data dikatakan stasioner jika mean, varian dan kovarian setiap lag konstan pada setiap waktu. Jika data runtun waktu tidak memenuhi kriteria tersebut, maka dapat dikatakan bahwa data tersebut tidak stasioner. Metode sederhana untuk menguji apakah data stasioner atau tidak adalah dengan melihat plot autocorrelation function (ACF).

\subsubsection{Uji Augmented Dickey-Fuller (ADF)}

Uji stasioneritas menggunakan uji ADF dapat dilakukan dengan langkah berikut:

Hipotesis:

$\mathrm{H}_{0}: \delta=0$ (terdapat akar unit atau data tidak stasioner)

$\mathrm{H}_{1}: \delta<0$ (tidak terdapat akar unit atau data stasioner)

Statistik Uji:

$A D F=\frac{\widehat{\delta}}{S E(\widehat{\delta})}$

Kriteria $\mathrm{Uji}: \mathrm{H}_{0}$ ditolak jika $\mathrm{ADF}<$ nilai tabel $\mathrm{ADF}$ atau $p$-value $<\alpha$.

\subsubsection{Fungsi Autokorelasi (FAK)}

Sebuah proses stasioner $\left(Z_{t}\right)$ terdapat mean $E\left(Z_{t}\right)=\mu$ dan variansi $\operatorname{Var}\left(Z_{t}\right)=E\left(Z_{t}-\right.$ $\mu)^{2}=\sigma^{2}$ yang bernilai konstan, $\operatorname{dan} \operatorname{Cov}\left(Z_{t}, Z_{s}\right)$ merupakan fungsi kovarian pada selisih waktu $|\mathrm{t}-\mathrm{s}|$.

\subsubsection{Fungsi Autokorelasi Parsial (FAKP)}

Menurut Wei (2006), autokorelasi parsial digunakan untuk mengukur tingkat keeratan antara $Z_{t}$ dan $Z_{t+k}$ setelah pengaruh terhadap variabel $Z_{t+1}, Z_{t+2}, \ldots$, dan $Z_{t+k-1}$ dihapus.Secara umum nilai fungsi autokorelasi parsial (PACF) pada lag ke-k adalah:

$$
\emptyset_{k k}=\frac{\left|\begin{array}{cccccc}
1 & \rho_{1} & \rho_{2} & \cdots & \rho_{k-2} & \rho_{1} \\
\rho_{1} & 1 & \rho_{1} & \cdots & \rho_{k-3} & \rho_{2} \\
\vdots & \vdots & \vdots & \ddots & \vdots & \vdots \\
\rho_{k-1} & \rho_{k-2} & \rho_{k-3} & \cdots & \rho_{1} & \rho_{k}
\end{array}\right|}{\left|\begin{array}{cccccc}
1 & \rho_{1} & \rho_{2} & \cdots & \rho_{k-2} & \rho_{k-1} \\
\rho_{1} & 1 & \rho_{1} & \cdots & \rho_{k-3} & \rho_{k-2} \\
\vdots & \vdots & \vdots & \ddots & \vdots & \vdots \\
\rho_{k-1} & \rho_{k-2} & \rho_{k-3} & \cdots & \rho_{1} & 1
\end{array}\right|}
$$

\subsection{Model Time Series ARMA}

Model time series ARMA dapat dibedakan menjadi:

a. Model AR dapat dituliskan sebagai berikut: 


$$
Z_{t=} \emptyset_{1} Z_{t-1}+\emptyset_{2} Z_{t-2}+\ldots .+\emptyset_{p} Z_{t-p}+a_{t}
$$

b. Model MA dapat dituliskan sebagai berikut:

$$
Z_{t}=a_{t}-\theta_{1} a_{t-1}-\theta_{2} a_{t-2}-\ldots .-\theta_{q} a_{t-q}
$$

c. Model ARMA dapat dituliskan sebagai berikut:

$$
Z_{t}=\emptyset_{1} Z_{t-1}+\emptyset_{2} Z_{t-2}+\ldots .+\emptyset_{p} Z_{t-p}+a_{t}-\theta_{1} a_{t-1}-\theta_{2} a_{t-2}-\ldots-\theta_{q} a_{t-q}
$$

\subsection{Model ARMA dengan Box-Jenkins}

\subsubsection{Estimasi Parameter dan Uji Signifikansi Parameter Model}

Pengujian signifikansi parameter dapat dilakukan dengan langkah berikut: Hipotesis:

1) Uji signifikansi parameter $A R$

$\mathrm{H}_{0}: \phi_{i}=0$ (parameter tidak signifikan terhadap model)

$\mathrm{H}_{1}: \phi_{i} \neq 0$ (parameter signifikan terhadap model)

2) Uji signifikansi parameter MA

$\mathrm{H}_{0}: \theta_{j}=0$ (parameter tidak signifikan terhadap model)

$\mathrm{H}_{1}: \theta_{j} \neq 0$ (parameter signifikan terhadap model)

Statistik uji:

1) Parameter AR: t-hitung $=\frac{\widehat{\phi}_{i}}{\operatorname{SE}\left(\widehat{\phi}_{i}\right)}$

2) Parameter MA: t-hitung $=\frac{\widehat{\theta}_{j}}{\operatorname{SE(\widehat {\theta }_{j})}}$

Kriteria uji:Tolak $\mathrm{H}_{0}$ jika $|\mathrm{t}-\mathrm{hitung}|>t_{\left(\frac{\alpha}{2} ; n-(p+q)\right)}$ atau $p$-value $<\alpha$

\subsection{Uji Asumsi Residual Model ARIMA}

\subsubsection{Uji White Noise Residual Model ARIMA}

Uji independensi residual digunakan untuk mendeteksi apakah ada korelasi antar lag. Metode yang digunakan adalah metode Ljung-Box.

Hipotesis:

$\mathrm{H}_{0}: \rho_{1}=\rho_{2}=\cdots=\rho_{K}=0$ (tidak terdapat korelasi residual antar lag)

$\mathrm{H}_{1}$ : Paling sedikit ada satu $\rho_{k} \neq 0$ dengan $\mathrm{k}=1,2, \ldots, \mathrm{K}$ (terdapat korelasi residual antar lag)

Statistik uji: $Q=n(n+2) \sum_{k=1}^{K} \frac{\widehat{\rho}_{k}^{2}}{n-k}$

Kriteria uji:Tolak $\mathrm{H}_{0}$ jika $Q>\chi_{(\alpha ; K-(p+q))}^{2}$ atau $p$-value $<\alpha$

\subsubsection{Uji Normalitas Residual Model ARIMA}

Uji normalitas residual digunakan untuk mengetahui apakah residual berdistribusi normal atau tidak. Uji normalitas menggunakan uji Kolmogorov Smirnov.

Hipotesis:

$\mathrm{H}_{0}: F\left(a_{t}\right)=F_{0}\left(a_{t}\right)$ untuk semua nilai $a_{t}$ (residual data berdistribusi normal)

$\mathrm{H}_{1}: F\left(a_{t}\right) \neq F_{0}\left(a_{t}\right)$ untuk sekurang-kurangnya sebuah nilai $a_{t}$ (residual data tidak berdistribusi normal)

Statistik Uji: $D=\sup \left|S\left(a_{t}\right)-F_{0}\left(a_{t}\right)\right|$

Kriteria uji:Tolak $\mathrm{H}_{0}$ jika $D>D_{1-\alpha / 2}$ atau $p$-value $<\alpha$.

\subsubsection{Uji Efek ARCH}

Hipotesis:

$\mathrm{H}_{0}: \alpha_{1}=\alpha_{2}=\cdots=\alpha_{q}=0$ (tidak ada efek ARCH atau varian residual homogen) 
$\mathrm{H}_{1}$ : Paling sedikit ada satu $\alpha_{k} \neq 0$ dengan $\mathrm{k}=1,2, \ldots, \mathrm{q}$ (ada efek $\mathrm{ARCH}$ atau varian residual tidak homogen)

Statistik uji: $\quad L M=n R^{2}$

Kriteria uji: $\quad$ Tolak $\mathrm{H}_{0}$ jika $L M>\chi_{(\alpha ; q)}^{2}$ atau $p$-value $<\alpha$

\subsection{Model ARCH/GARCH}

Model ARCH/GARCH dapat dibedakan menjadi:

a. Model ARCH dapat dituliskan sebagai berikut:

$$
\sigma_{t}^{2}=\alpha_{0}+\alpha_{1} a_{t-1}^{2}+\cdots+\alpha_{q} \alpha_{t-q}^{2}
$$

b. Model GARCH dapat dituliskan sebagai berikut:

$$
\sigma_{t}^{2}=\alpha_{0}+\sum_{i=1}^{q} \alpha_{i} a_{t-i}^{2}+\sum_{j=1}^{p} \beta_{j} \sigma_{t-j}^{2}
$$

\subsubsection{Uji Signifikansi Parameter Model ARCH/GARCH}

Pengujian signifikansi parameter dapat dilakukan dengan langkah berikut: Hipotesis:

1) Uji signifikansi parameter model $\mathrm{ARCH}$

$\mathrm{H}_{0}: \boldsymbol{\alpha}_{\boldsymbol{i}}=\mathbf{0}, \mathrm{i}=0,1, \ldots, \mathrm{q}$ (parameter tidak signifikan)

$\mathrm{H}_{1}$ : Paling sedikit ada satu $\boldsymbol{\alpha}_{\boldsymbol{i}} \neq \mathbf{0}$ (parameter signifikan)

2) Uji signifikansi parameter model GARCH

$\mathrm{H}_{0}: \boldsymbol{\beta}_{\boldsymbol{j}}=\mathbf{0}, \mathrm{j}=0,1, \ldots, \mathrm{p}$ (parameter tidak signifikan)

$\mathrm{H}_{1}$ : Paling sedikit ada satu $\boldsymbol{\beta}_{\boldsymbol{j}} \neq \mathbf{0}$ (parameter signifikan)

Statistik uji:

1) Parameter ARCH: t-hitung $=\frac{\widehat{\boldsymbol{\alpha}}_{i}}{\boldsymbol{S E}\left(\widehat{\boldsymbol{\alpha}}_{i}\right)}$

2) Parameter GARCH: t-hitung $=\frac{\widehat{\widehat{\boldsymbol{\beta}}}_{j}}{\boldsymbol{S E}\left(\widehat{\boldsymbol{\beta}}_{j}\right)}$

Kriteria uji:Tolak $\mathrm{H}_{0}$ jika $\mid \mathrm{t}$-hitung $\mid>\boldsymbol{t}_{\frac{\alpha}{2}, \boldsymbol{n}-(\boldsymbol{p}+\boldsymbol{q})}$ atau $p$-value $<\alpha$

\subsection{Pemilihan Model Terbaik}

Ada beberapa cara untuk menentukan model terbaik, salah satunya adalah dengan menggunakan kriteria AIC (Akaike's Information Creation). Model terbaik dipilih jika memiliki nilai AIC yang terkecil. Menurut Wei (2006), rumus AIC adalah:

$$
A I C=n \ln \left(\widehat{\sigma}_{t}^{2}\right)+2 k
$$

\subsection{Analisis Intervesi}

Data runtun waktu seringkali terpengaruh oleh kejadian eksternal seperti hari libur, promosi, dan berbagai kebijakan lainnya. Tujuan utama dari analisis ini adalah mengukur besar dan lamanya efek intervensi pada suatu runtun waktu. Menurut Wei (2006), bentuk umum dari model intervensi adalah:

$$
Z_{t}=\theta_{0}+\sum_{j=1}^{k} \frac{\omega_{s j}(B) B^{b j}}{\delta_{r j}(B)} I_{j t}+\frac{\theta_{q}(B)}{\phi_{p}(B)} a^{t}
$$

Menurut Nuvitasari (2009) orde b, s dan r merupakan hal yang penting dalam pemodelan intervensi. Orde dapat diidentifikasi dengan melihat plot residual yang diperoleh dari selisih antara data setelah intervensi dengan hasil peramalan dari data sebelum intervensi. Orde b ditentukan dengan melihat kapan efek intervensi mulai terjadi, 
orde s menunjukkan kapan gerak bobot respon mulai menurun atau mulai berada dalam batas signifikan, orde $\mathrm{r}$ merupakan $\mathrm{r}$ time lag berikutnya (setelah $\mathrm{b}$ dan $\mathrm{s}$ ) saat data membentuk pola yang jelas.

Secara umum ada dua jenis variabel intervensi, yaitu fungsi step dan fungsi pulse. Fungsi step digunakan pada intervensi yang bersifat jangka panjang, seperti pergantian presiden, kebijakan pemerintah, kebijakan perusahaan dan lain-lain.Secara matematis, bentuk intervensi fungsi step dapat dinotasikan sebagai berikut:

$$
I_{t}=S_{t}= \begin{cases}0 & t<T \\ 1 & t \geq T\end{cases}
$$

Sedangkan fungsi pulse digunakan pada intervensi yang bersifat sementara atau jangka pendek, seperti bencana alam, bom, demokrasi, dan lain-lain. Secara matematis, bentuk intervensi fungsi pulse dapat dinotasikan sebagai berikut:

$$
I_{t}=P_{t}= \begin{cases}0 & t \neq T \\ 1 & t=T\end{cases}
$$

\subsection{Pasar Modal}

Pasar modal pada hakikatnya adalah jaringan aturan yang memungkinkan pertukaran klaim jangka panjang, penambahan asset keuangan dan hutang pada saat yang sama, memungkinkan investor untuk mengubah dan menyesuaikan portofolio investasi melalui pasar sekunder (Anoraga dan Piji, 2006).

Menurut Utami (2010), pasar modal memiliki dua fungsi yaitu fungsi ekonomi dan keuangan. Dikatakan memiliki fungsi ekonomi karena menyediakan sarana yang mempertemukan pihak investor (pemberi dana) dan pihak yang memerlukan dana (perusahaan). Sedangkan dikatakan memiliki fungsi keuangan karena investor (pemilik dana) dapat mendapatkan untung setelah melakukan investasi. Oleh karena itu, pasar modal ini diharapkan mampu meningkatkan aktivitas perekonomian negara.

\subsection{Saham}

Salah satu produk investasi yang paling banyak diperdagangkan di pasar modal adalah saham. Menurut Bursa Efek Indonesia (2018), saham dapat didefinisikan sebagai bukti kepemilikan seseorang atau badan atas suatu perusahaan yang merupakan klaim atas penghasilan dan kekayaan perseroan. Apabila seorang investor membeli saham, maka secara otomatis akan menjadi pemilik dan disebut sebagai pemegang saham tersebut.

\subsection{Return}

Return adalah hasil, baik keuntungan maupun kerugian, yang didapatkan pihak investor dari hasil investasi yang dilakukan. Salah satu factor yang membuat para investor menanamkan modalnya saat berinvestasi adalah return yang tinggi, karena dengan return yang tinggi maka investor berharap akan mendapatkan imbalan yang tinggi dari investasi yang dilakukan.Return dapat dihitung menggunakan logaritma natural atau Continuous Compounding Return dengan rumus sebagai berikut:

$$
\mathrm{R}\left(\mathrm{P}_{\mathrm{t}}\right)=\ln \left(\mathrm{P}_{\mathrm{t}}\right)-\ln \left(\mathrm{P}_{\mathrm{t}-1}\right)
$$

\section{METODOLOGI PENELITIAN}

\subsection{Jenis dan Sumber Data}

Pada penelitian ini jenis data yang digunakan adalah data sekunder, yaitu data bulanan return saham PT Bayan Resources Tbk periode Agustus 2008 sampai dengan September 2018 yang diperoleh dari website Yahoo Finance (www.finance.yahoo.com). Penelitian ini menggunakan data return saham PT Bayan Resources Tbk sebanyak 122 data. 


\subsection{Teknik Pengolahan Data}

1. Mengubah data saham PT Bayan Resources Tbk menjadi data return.

2. Membuat plot time series untuk melihat pola respon intervensi dan menduga variabel intervensi yang mungkin.

3. Mengidentifikasi model ARIMA dari data sebelum intervensi yang didahului pemeriksaan stasioneritas dalam rata-rata dan varians untuk data awal berdasarkan plot time series yang telah dibuat. Setelah stasioner, dibuat grafik FAK dan FAKP untuk menentukan model ARIMA yang sesuai.

4. Estimasi parameter model ARIMA dari data sebelum terjadinya intervensi.

5. Verifikasi model dengan menggunakan uji independensi residual dan uji normalitas residual.

6. Evaluasi model ARIMA.

7. Melakukan peramalan untuk data sebelum terjadinya intervensi sampai dengan intervensi terpenuhi berdasarkan model ARIMA terbaik.

8. Menghitung residual respon antara data setelah intervensi dengan hasil peramalan dari data sebelum intervensi.

9. Mengidentifikasi pola respon intervensi dan membentuk model intervensi melalui plot residual. Plot ini digunakan dalam menentukan orde b, s, dan r.

10. Melakukan estimasi parameter model intervensi dan verifikasi model intervensi.

11. Evaluasi model intervensi.

12. Melakukan uji Lagrange Multiplier terhadap data kuadrat residual dari model intervensi untuk mengetahui apakah terdapat efek ARCH/GARCH pada model.

13. Identifikasi model ARCH/GARCH.

14. Melakukan estimasi parameter model ARCH/GARCH.

15. Memilih model ARCH/GARCH terbaik.

\section{HASIL DAN PEMBAHASAN}

\subsection{Pemodelan ARMA sebelum Intervensi}

Pemodelan ARMA pada data return harga saham dilakukan pada data sebelum terjadinya intervensi yaitu pada Agustus $2008(\mathrm{t}=1)$ sampai Agustus $2017(\mathrm{t}=109)$. Berikut ini adalah tabel hasil kesimpulan dari pengujian signifikansi parameter, pengujian asumsi independensi residual dan asumsi normalitas residual, serta nilai AIC untuk masing-masing model ARMA yang mungkin untuk data sebelum intervensi.

Tabel 1. Evaluasi Model ARMA sebelum Intervensi

\begin{tabular}{ccccc}
\hline Model & $\begin{array}{c}\text { Signifikansi } \\
\text { Parameter }\end{array}$ & $\begin{array}{l}\text { White } \\
\text { Noise }\end{array}$ & Normalitas & AIC \\
\hline ARMA $(0,1)$ & Ya & Tidak & Tidak & $-151,558$ \\
ARMA $(0,[2])$ & Ya & Tidak & Tidak & $-135,124$ \\
ARMA $(1,0)$ & Ya & Tidak & Tidak & $-154,747$ \\
ARMA $([1,4], 0)$ & Ya & Ya & Tidak & $-158,885$ \\
ARMA $([1,4], 1)$ & Ya & Ya & Tidak & $-159,447$ \\
\hline
\end{tabular}

Berdasarkan Tabel 1, dapat disimpulkan bahwa model ARMA([1,4],0) dan $\operatorname{ARMA}([1,4], 1)$ mempunyai parameter yang signifikan, residual independen dan AIC yang kecil.

\subsection{Analisis Intervensi}

\subsubsection{Penentuan Orde Intervensi}

Pada tahap ini akan ditentukan orde dari model intervensi dengan cara membuat plot residual dari peramalan data berdasarkan model ARIMA sebelum intervensi. Residual 
respon intervensi didapat dari selisih nilai aktual dikurangi nilai peramalan. Batas yang digunakan untuk menentukan garis signifikansi adalah $\pm \sigma$ yang didapatkan melalui perhitungan standar deviasi residual model ARIMA sebelum intervensi.
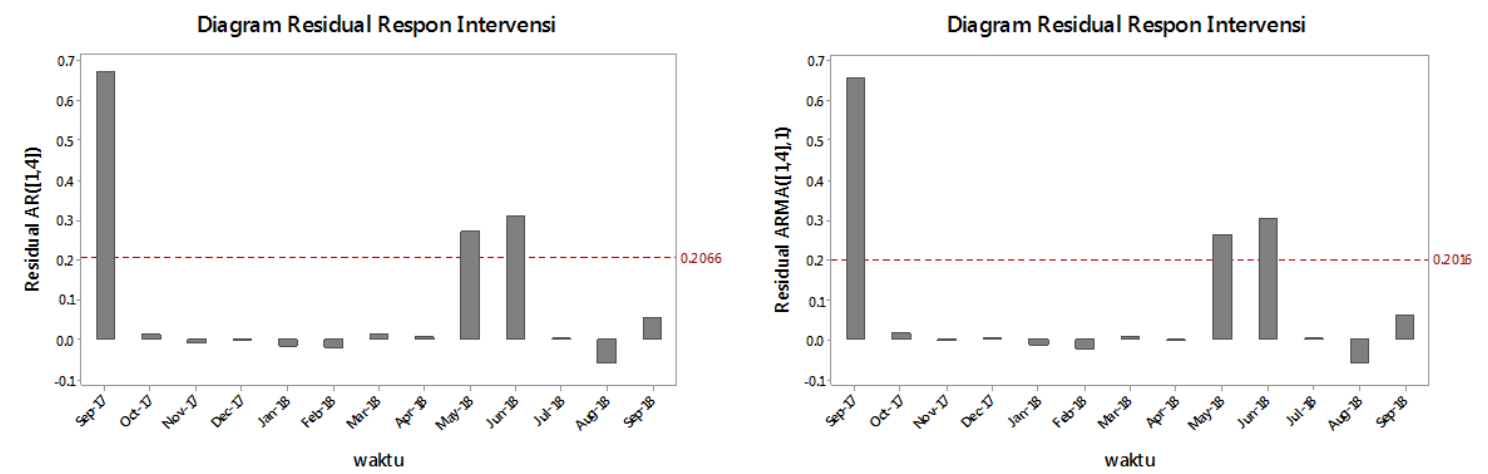

Gambar 1. Diagram Residual Respon ARMA([1,4],0) dan ARMA([1,4],1)

Dari Gambar 1 plot residual respon keluar langsung dari garis signifikansi pada September 2017 yang artinya intervensi terjadi pada saat itu juga yang berarti waktu tunda atau nilai b adalah 0 . Pada Oktober 2017 plot residual langsung turun yang menyebabkan residual respon keluar batas signifikansi sehingga didapatkan nilai s adalah 0. Pada Gambar 1 terlihat bahwa ada 2 lag yang keluar dari batas signifikan sehingga dapat dicoba nilai $r+s=2$. Berdasarkan analisis tersebut, akan diperoleh model intervensi dengan dugaan orde $(b=0, s=0, r=0),(b=0, s=2, r=0),(b=0, s=1, r=1)$, dan $(b=0, s=0, r=2)$.

\subsubsection{Pemodelan Intervensi}

Setelah diperoleh dugaan model intervensinya, maka model yang memungkinkan kemudian dilakukan uji diagnostik. Berikut ini adalah tabel hasil kesimpulan dari pengujian signifikansi parameter, pengujian asumsi independensi residual dan asumsi normalitas residual, serta nilai AIC untuk masing-masing model intervensi yang mungkin.

Tabel 2. Evaluasi Model Intervensi

\begin{tabular}{ccccc}
\hline Model & $\begin{array}{c}\text { Signifikansi } \\
\text { Parameter }\end{array}$ & $\begin{array}{c}\text { White } \\
\text { Noise }\end{array}$ & Normalitas & \multirow{2}{*}{ AIC } \\
\hline ARMA $([1,4], 0) \mathrm{b}=0, \mathrm{~s}=0, \mathrm{r}=0$ & Ya & Ya & Tidak & $-178,186$ \\
ARMA $([1,4], 0) \mathrm{b}=0, \mathrm{~s}=1, \mathrm{r}=1$ & Ya & Ya & Tidak & $-179,411$ \\
\hline
\end{tabular}

Berdasarkan Tabel 2, dapat disimpulkan bahwa model ARMA([1,4],0) $\bar{b}=0, \mathrm{~s}=0$, $\mathrm{r}=0$ dan $\operatorname{ARMA}([1,4], 0) \mathrm{b}=0, \mathrm{~s}=1, \mathrm{r}=1$ mempunyai parameter yang signifikan, residual independen dan AIC yang kecil.

\subsection{Pemodelan ARCH/GARCH}

Model intervensi yang parameternya sudah signifikan dan asumsi residualnya terpenuhi kemudian dilakukan pengujian apakah terdapat efek heteroskedastisitas atau efek ARCH pada residual modelnya. Jika terdapat edek ARCH pada model intervensi, maka dilakukan pemodelan ARCH/GARCH yang mampu mengatasi keberadaan heteroskedastisitas atau efek ARCH.Berikut ini adalah tabel hasil kesimpulan dari pengujian signifikansi parameter untuk masing-masing model ARCH/GARCH. 
Tabel 3.Uji Signifikansi Parameter Model ARCH/GARCH

\begin{tabular}{clc}
\hline Model Rataan & Model Varian & Signifikansi Parameter \\
\hline ARMA $([1,4], 0) \mathrm{b}=0, \mathrm{~s}=0, \mathrm{r}=0$ & $\operatorname{ARCH}(1)$ & Ya \\
& $\operatorname{ARCH}(2)$ & Tidak \\
& GARCH $(1,1)$ & Ya \\
ARMA $([1,4], 0) \mathrm{b}=0, \mathrm{~s}=1, \mathrm{r}=1$ & $\operatorname{ARCH}(1)$ & Tidak \\
& ARCH $(2)$ & Tidak \\
& GARCH $(1,1)$ & Tidak \\
& GARCH $(1,2)$ & Ya \\
& GARCH $(2,1)$ & Tidak \\
\hline
\end{tabular}

Berdasarkan Tabel 3, dapat disimpulkan bahwa model $\overline{\operatorname{ARMA}([1,4], 0), b}=0, s=0$, $\mathrm{r}=0-\operatorname{ARCH}(1), \operatorname{ARMA}([1,4], 0), \mathrm{b}=0, \mathrm{~s}=0, \mathrm{r}=0-\mathrm{GARCH}(1,1)$ dan $\operatorname{ARMA}([1,4], 0), \mathrm{b}=0$, $\mathrm{s}=1, \mathrm{r}=1-\mathrm{GARCH}(1,1)$ mempunyai parameter yang signifikan.

\subsection{Pemilihan Model Terbaik}

Pemilihan model terbaik dilakukan dengan cara memilih model yang memiliki nilai AIC terkecil. Berikut ini adalah tabel hasil kesimpulan dari pengujian signifikansi parameter dan nilai AIC untuk masing-masing model ARCH/GARCH.

Tabel 4. Nilai AIC Model ARCH/GARCH dengan Pendekatan Model Intervensi

\begin{tabular}{ccc}
\hline Model Rataan & Model Varian & AIC \\
\hline ARMA $([1,4], 0)$, & ARCH $(1)$ & $-186,64652$ \\
b=0, s=0,r=0 & GARCH $(1,1)$ & $-199,70463$ \\
ARMA $([1,4], 0)$, & GARCH $(1,1)$ & $-205,75088$ \\
b=0,s=1,r=1 & & \\
\hline
\end{tabular}

Berdasarkan Tabel 4, terlihat bahwa model ARMA([1,4],0), $\mathrm{b}=0, \mathrm{~s}=1, \mathrm{r}=1$ dengan model varian $\operatorname{GARCH}(1,1)$ memiliki nilai AIC terkecil, sehingga model tersebut merupakan model terbaik.Model $\operatorname{ARMA}([1,4], 0), \quad b=0, s=1, r=1$ dapat ditulis dengan persamaan:

$$
Z_{t}=0,6649 P_{t}-0,00183 P_{t-1}-0,84169 P_{t-2}+\frac{a_{t}}{\left(1-0,46066 B+0,22429 B^{4}\right)}
$$

Sedangkan model GARCH(1,1) dapat ditulis dengan persamaan:

$$
\sigma_{t}^{2}=0,001648+0,2318 a_{t-1}^{2}+0,6656 \sigma_{t-1}^{2}
$$

\section{KESIMPULAN}

Berdasarkan pada hasil analisis penelitian yang telah dilakukan, dapat disimpulkan beberapa hal sebagai berikut:

1. Model intervensi yang dapat teridentifikasi dan memiliki parameter-parameter signifikan adalah ARMA([1,4],0) $(b=0, s=0, r=0)$ dan $\operatorname{ARMA}([1,4], 0)(b=0, s=1$, $\mathrm{r}=1$ ).

2. Model intervensi fungsi pulse yang terbaik adalah $\operatorname{ARMA}([1,4], 0)(b=0, s=1, r=1)$ dengan AIC sebesar -179,411.

Model tersebut ditulis dengan persamaan:

$$
Z_{t}=0,6649 P_{t}-0,00183 P_{t-1}-0,84169 P_{t-2}+\frac{a_{t}}{\left(1-0,46066 B+0,22429 B^{4}\right)}
$$

3. Model Intervensi-ARCH/GARCHyang dapat teridentifikasi dan memiliki parameter-parameter signifikan adalah $\operatorname{ARMA}([1,4], 0)(b=0, s=0, r=0)-\operatorname{ARCH}(1)$, 
$\operatorname{ARMA}([1,4], 0) \quad(b=0, s=0, r=0)-\operatorname{GARCH}(1,1) \quad$ dan $\operatorname{ARMA}([1,4], 0) \quad(b=0, s=1$, $\mathrm{r}=1)-\mathrm{GARCH}(1,1)$.

4. Model ARCH/GARCH dengan pendekatan model intervensi yang terbaik adalah GARCH(1,1) dengan AIC sebesar -205,75088. Sehingga diperoleh model akhir $\operatorname{ARMA}([1,4], 0)(b=0, s=1, r=1)-\operatorname{GARCH}(1,1)$.

Model GARCH $(1,1)$ ditulis dengan persamaan:

$$
\sigma_{t}^{2}=0,001648+0,2318 a_{t-1}^{2}+0,6656 \sigma_{t-1}^{2}
$$

\section{DAFTAR PUSTAKA}

Anoraga, P., dan Piji, P. 2006. Pengantar Pasar Modal. Jakarta: Rineka Cipta.

Bollerslev. 1986. Generalized Autoregressive Conditional Heteroscedasticity. Journal of Econometrics Vol. 31: 307-327.

Brooks, C. 2008. Introductory Econometrics for Finance. $2^{\text {nd }}$ Edition. Cambridge: Cambridge University Press.

Bursa Efek Indonesia. 2018. Modul Sekolah Pasar Modal Level 1. Bursa Efek Indonesia.

Daniel, W.W. 1989. Statistika Nonparametrik Terapan. Terjemahan dari: Alex Tri Kantjono W. Jakarta: Gramedia.

Gujarati, D.N. 2004. Basic Econometrics. $4^{\text {th }}$ Edition. New York: The McGraw - Hill Companies.

Makridakis, S., Wheelwright, S.C., dan McGee, V.E. 1995. Metode dan Aplikasi Peramalan. Jilid satu. Edisi Kedua. (diterjemahkan oleh: Adriyanto, Untung Sus dan Basith, Abdul). Jakarta: Erlangga.

Nuvitasari, E. 2009. Analisis Intervensi Multi Input Fungsi Step dan Pulse untuk Peramalan Kunjungan Wisatawan ke Indonesia. Tesis. Surabaya: ITS.

Rosadi, D. 2012. Ekonometrika \& Analisis Runtun Waktu Terapan dengan Eviews. Yogyakarta: Penerbit ANDI.

Soejoeti, Z. 1987. Analisis Runtun Waktu. Jakarta: Karunika Universitas Terbuka.

Tsay, R.S. 2002. Analysis of Financial Time Series. New York: John Wiley \& Sons, Inc.

Utami, E.T. 2010. Cara Cerdas Berinvestasi via Online Trading. Jakarta: TransMedia Pustaka.

Wei, W.W.S. 2006. Time Series Analysis: Univariate and Multivariate Methods. $2^{\text {nd }}$ Edition. Canada: Addison Wesley Publishing Company.

Widarjono, A. 2013. Ekonometrika: Pengantar dan Aplikasinya Disertai Panduan Eviews. Yogyakarta: UPP STIM YKPN. 